
Not for reproduction, distribution or commercial use.

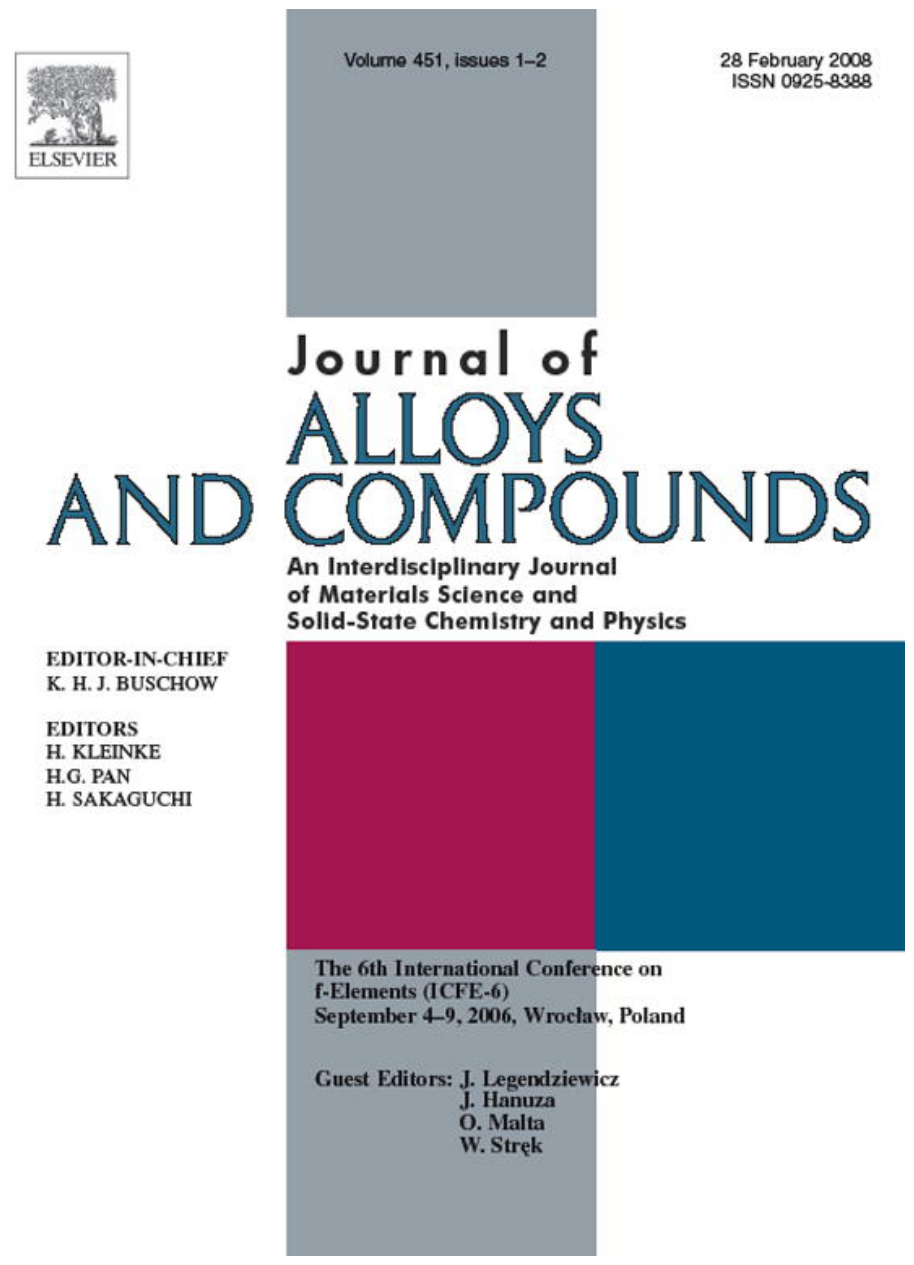

This article was published in an Elsevier journal. The attached copy

is furnished to the author for non-commercial research and education use, including for instruction at the author's institution, sharing with colleagues and providing to institution administration.

Other uses, including reproduction and distribution, or selling or licensing copies, or posting to personal, institutional or third party websites are prohibited.

In most cases authors are permitted to post their version of the article (e.g. in Word or Tex form) to their personal website or institutional repository. Authors requiring further information regarding Elsevier's archiving and manuscript policies are encouraged to visit: 


\title{
Excitation of inter- and intraconfigurational luminescence of trivalent rare earth ions in strontium fluoride crystals
}

\author{
K.V. Ivanovskikh*, V.A. Pustovarov, A. Smirnov, B.V. Shulgin \\ Ural State Technical University-UPI, Mira st. 19, 620002 Ekaterinburg, Russia
}

Available online 13 April 2007

\begin{abstract}
Excitation spectra for intraconfigurational $\left(4 \mathrm{f}^{n} \rightarrow 4 \mathrm{f}^{n}\right)$ and interconfigurational $\left(4 \mathrm{f}^{n-1} 5 \mathrm{~d} \rightarrow 4 \mathrm{f}^{n}\right)$ radiative transitions of trivalent rare earth ions $\left(\mathrm{Sm}^{3+}, \mathrm{Tb}^{3+}, \mathrm{Er}^{3+}\right.$, and $\left.\mathrm{Tm}^{3+}\right)$ doped into $\mathrm{SrF}_{2}$ crystals have been studied using VUV synchrotron radiation and analyzed. The distinctions and peculiarities of excitation mechanisms for $4 \mathrm{f}^{n}$ or $4 \mathrm{f}^{n-1} 5 \mathrm{~d}$ emitting levels are discussed.
\end{abstract}

(c) 2007 Elsevier B.V. All rights reserved.

Keywords: Rare earth ions; Luminescence; Excitation; VUV spectroscopy

\section{Introduction}

Luminescent vacuum ultraviolet (VUV) spectroscopy of rare earth (RE) ions doped into wide band crystals has attracted considerable research interest recently that is inspired by numerous applications for materials with optical activity in the VUV range. Researches on the VUV spectroscopy are focused on understanding the level structure and relaxation mechanisms from high-energy localized states formed by mixed $4 \mathrm{f}^{n-1} 5 \mathrm{~d}$ configurations predominantly. Moreover, one of the important problems is connected with research of energy transfer processes to emitting levels of impurity ions [1].

From these points of view we carried out an experimental study in VUV range for $\mathrm{Sm}^{3+}\left(4 \mathrm{f}^{5}\right), \mathrm{Tb}^{3+}\left(4 \mathrm{f}^{8}\right), \mathrm{Er}^{3+}\left(4 \mathrm{f}^{11}\right)$ and $\mathrm{Tm}^{3+}\left(4 \mathrm{f}^{12}\right)$ ions in $\mathrm{SrF}_{2}$ crystals which are among the promising materials. In spite of the fact that $\mathrm{SrF}_{2}: \mathrm{RE}^{3+}$ crystals are sufficiently studied systems in the past the special attention to the VUV spectroscopy properties has not been paid to these systems recently.

The $5 \mathrm{~d}$ levels of $\mathrm{RE}^{3+}$ ions doped into fluorite crystals are split by cubic Oh crystal field into low-energy doublet ${ }^{2} \mathrm{E}-$ and high-energy triplet ${ }^{2} \mathrm{~T}_{2}$ subconfigurations. The interconfigurational $4 \mathrm{f}^{n} \rightarrow 4 \mathrm{f}^{n-1} 5 \mathrm{~d}$ transitions are more likely to the lowest tetragonal ${ }^{2} \mathrm{E}$ component $\left(x^{2}-y^{2}\right.$-orbital) and to the states

\footnotetext{
* Corresponding author at: Experimental Physics Department, Urals State Technical University, Mira Street 19, 620002 Ekaterinburg, Russia. Tel.: +7 343 3754876; fax: +7 3433743884 .

E-mail address: ivanovskikh@inbox.ru (K.V. Ivanovskikh).
}

of ${ }^{2} \mathrm{~T}_{2}$ subconfigurations ( $x y-, x z-$, and $y z$-orbitals) [2]. An excellent overview and detailed analysis of $4 \mathrm{f}^{n} \rightarrow 4 \mathrm{f}^{n-1} 5 \mathrm{~d}$ excitation spectra for all $\mathrm{RE}^{3+}$ ions in $\mathrm{YPO}_{4}, \mathrm{CaF}_{2}$ and $\mathrm{LiYF}_{4}$ have been presented in Refs. [3-5]. The authors have been showed a new method for identification of $4 \mathrm{f}^{n-1} 5 \mathrm{~d}$ states in the spectra.

Our recent studies of VUV emission and $4 \mathrm{f}^{n} \rightarrow 4 \mathrm{f}^{n-1} 5 \mathrm{~d}$ excitation spectra of $\mathrm{RE}^{3+}$ ions doped into $\mathrm{SrF}_{2}$ have been shown in Refs. [6-8]. A continuation of these studies as well as new results and discussions concerning peculiarities of excitation mechanisms for intraconfigurational $\left(4 \mathrm{f}^{n} \rightarrow 4 \mathrm{f}^{n}\right)$ and interconfigurational $\left(4 \mathrm{f}^{n-1} 5 \mathrm{~d} \rightarrow 4 \mathrm{f}^{n}\right)$ radiative transitions have been presented in this paper.

\section{Experimental details}

The investigations were performed at the SUPERLUMI station (DESY, Hamburg). For excitation in $110-270 \mathrm{~nm}$ spectral range a $2 \mathrm{~m}$ monochromator in McPherson mounting with a resolution of $3.2 \AA$ was used. In VUV range the spectral selection for excitation spectra measurements were performed with a $0.5 \mathrm{~m}$ Pouey-type monochromator (with a resolution of $10 \AA ̊$ ) equipped with a solar-blind photomultiplier R6836 (Hamamatsu). For detection of visible luminescence an ARC Spectra Pro-308i spectrographmonochromator equipped with a photomultiplier R6358P (Hamamatsu) was used. The experiments were carried out a little above liquid He temperature at $8 \mathrm{~K}$.

$\mathrm{SrF}_{2}$ single crystals were grown in graphite crucible in fluorine atmosphere by the Stokbarger technique at Pyshminsky pilot plant GIRETMET (Russia). $\mathrm{RE}^{3+}$ ions were introduced in growth melt as $\mathrm{REF}_{3}$ compounds. Moreover, $\mathrm{PbF}_{2}$ was added to remove most of the oxygen from the melt. Nevertheless, in our estimation a permanent oxygen concentration was remained a little above $0.01 \mathrm{~mol} \%$. 


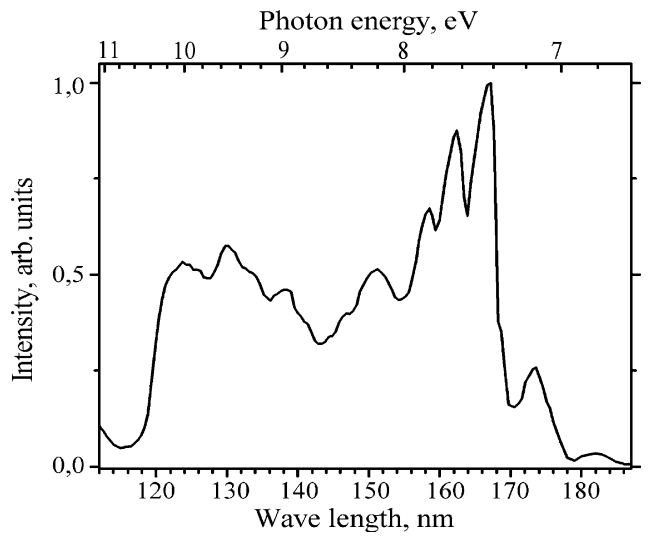

Fig. 1. Excitation spectrum for ${ }^{4} \mathrm{G}_{5 / 2} \rightarrow{ }^{6} \mathrm{H}_{7 / 2}$ emission at $598 \mathrm{~nm}$ of $\mathrm{Sm}^{3+}$ ions in $\mathrm{SrF}_{2}: 0.1 \% \mathrm{Sm}^{3+} . T=8 \mathrm{~K}$.

\section{Results and discussions}

Excitation spectra for $4 \mathrm{f}^{n} \rightarrow 4 \mathrm{f}^{n}$ emission of $\mathrm{Sm}^{3+}$ and $\mathrm{Tb}^{3+}$ in $\mathrm{SrF}_{2}$ crystals are shown in Figs. 1 and 2 correspondingly. Structure of these spectra is predominantly determined by parityallowed $4 \mathrm{f}^{n} \rightarrow 4 \mathrm{f}^{n-1} 5 \mathrm{~d}$ transitions to the different components of $4 \mathrm{f}^{n-1} 5 \mathrm{~d}$ configuration. The beginning of transitions to the lowest ${ }^{2} \mathrm{E}$ component is presented as a sharp increase of the

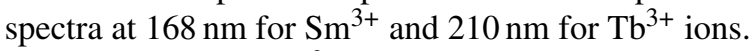

In the case of $\mathrm{Sm}^{3+}$ ions additional bands are caused by Coulomb interactions of the lowest ${ }^{2} \mathrm{E}$ state with various multiplets of residual $4 \mathrm{f}^{4}$ core of excited $4 \mathrm{f}^{4} 5 \mathrm{~d}$ configuration. The $4 \mathrm{f}^{4}$ core corresponds to non-excited $\mathrm{Pm}^{3+}$ ions, which has a dense enough levels set in wide energy range. Therefore, it is possible to conclude that additional bands make contribution to intensity of the spectra up to fundamental absorption edge of $\mathrm{SrF}_{2}$ at $119-121 \mathrm{~nm}$ [7]. Since crystal field splitting of $5 \mathrm{~d}$ orbital in $\mathrm{SrF}_{2}$ is about $19,800 \mathrm{~cm}^{-1}(2.45 \mathrm{eV})$ [9] it is possible to assume that transitions to the states involving the high-energy ${ }^{2} \mathrm{~T}_{2}$ subconfiguration are observed at $121-127 \mathrm{~nm}$.

The $4 \mathrm{f}^{7} 5 \mathrm{~d}$ states of $\mathrm{Tb}^{3+}$ spectra are unique and particularly accessible to analysis because the energy difference between the lowest state $\left({ }^{8} \mathrm{~S}_{7 / 2}\right)$ of residual $4 \mathrm{f}^{7}$ core and the next-lowest states $\left({ }^{6} \mathrm{P}_{\mathrm{J}}\right.$ and $\left.{ }^{6} \mathrm{I}_{\mathrm{J}}\right)$ exceed $30,000 \mathrm{~cm}^{-1}(3.72 \mathrm{eV})$, larger than

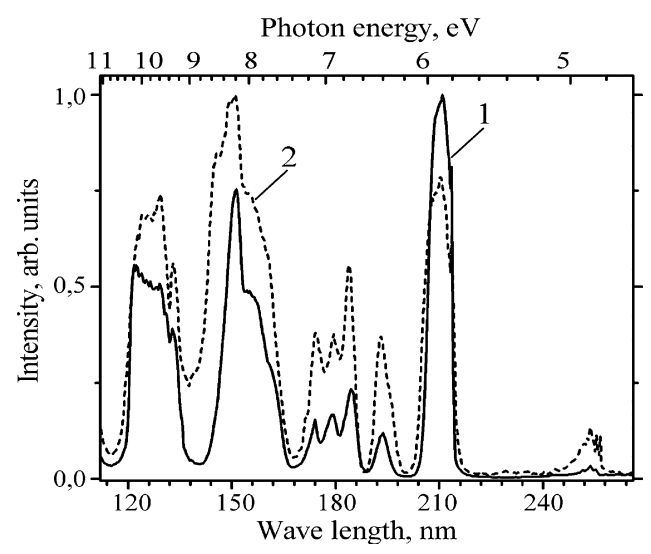

Fig. 2. Excitation spectra for ${ }^{5} \mathrm{D}_{3} \rightarrow{ }^{7} \mathrm{~F}_{6}$ emission at $385 \mathrm{~nm}$ of $\mathrm{Tb}^{3+}$ ions in $\mathrm{SrF}_{2}: 0.05 \% \mathrm{~Tb}^{3+}(1)$ and $\mathrm{SrF}_{2}: 1 \% \mathrm{~Tb}^{3+}(2) . T=8 \mathrm{~K}$.

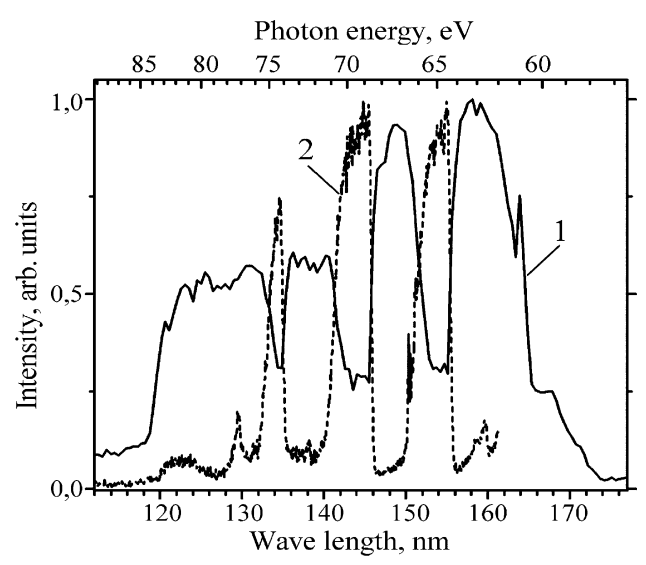

Fig. 3. Excitation spectra for ${ }^{4} \mathrm{~S}_{3 / 2} \rightarrow{ }^{4} \mathrm{I}_{15 / 2}$ emission at $550 \mathrm{~nm}$ (1) and for $4 \mathrm{f}^{10} 5 \mathrm{~d}(\mathrm{HS}) \rightarrow{ }^{4} \mathrm{I}_{15 / 2}$ emission at $165 \mathrm{~nm}$ (2) of $\mathrm{Er}^{3+}$ ions in $\mathrm{SrF}_{2}: 0.1 \% \mathrm{Er}^{3+}$. $T=8 \mathrm{~K}$.

crystal field splitting of $5 \mathrm{~d}$ orbital. So corresponded transitions to the lowest $x^{2}-y^{2}$ states of $4 \mathrm{f}^{7} 5 \mathrm{~d}$ configuration are observed as intensive bands at $210 \mathrm{~nm}$ and at $120-140 \mathrm{~nm}$. In our opinion, the transitions to the second $\left(z^{2}\right)$ tetragonal ${ }^{2} \mathrm{E}$ component are observed as $183.5 \mathrm{~nm}$ band. This band is $\sim 7700 \mathrm{~cm}^{-1}$ above low-energy side of $210 \mathrm{~nm}$ band that corresponds to energy difference between $x^{2}-y^{2}$ and $z^{2}$ states of $5 \mathrm{~d}$ orbital obtained for $\mathrm{Ce}^{3+}$ ions in $\mathrm{SrF}_{2}$ [2]. In accordance with crystal field splitting of $5 \mathrm{~d}$ orbital [9] the transitions to the high-energy triplet ${ }^{2} \mathrm{~T}_{2}$ set are presented in the spectra as broad bands at 145-172 nm.

Additional bands observed at 193, 180, and $174 \mathrm{~nm}$ cannot be surely explained by Coulomb interaction between $4 \mathrm{f}$ and $5 \mathrm{~d}$ electrons. It is needed to mention that in the works [3-5] the similar bands were observed in $\mathrm{LiYF}_{4}: 1 \% \mathrm{~Tb}^{3+}$ and not observed in $\mathrm{CaF}_{2}: 0.001 \% \mathrm{~Tb}^{3+}$. In our spectra considered bands also show larger intensity at higher concentration of impurity. In this connection, we assume that these bands can be connected with excitation of $\mathrm{RE}^{3+}$ centers situating in cluster formations which are effectively created at impurity concentration above $0.1 \%$ [10].

$\mathrm{Tb}^{3+}$ ions belong to subgroup of "heavy" lanthanides for which spin-forbidden transitions to high-spin (HS) states are possible [4]. In the spectra of $\mathrm{SrF}_{2}: \mathrm{Tb}^{3+}$ crystals such transitions are observed as low intensive bands at $255 \mathrm{~nm}$.

Excitation spectra of $\mathrm{Er}^{3+}$ and $\mathrm{Tm}^{3+}$ ions are presented in Figs. 3 and 4 correspondingly. For both ions the structure of $4 \mathrm{f}^{n-1} 5 \mathrm{~d}$ configuration is clearly observed in the spectra-recorded monitoring $4 \mathrm{f}^{n-1} 5 \mathrm{~d} \rightarrow 4 \mathrm{f}^{n}$ emission. The detailed analysis of these spectra can be found elsewhere $[6,8]$.

As is shown in the figures, the spectra-recorded monitoring $4 \mathrm{f}^{n} \rightarrow 4 \mathrm{f}^{n}$ emission demonstrates opposite behaviour to those for $4 \mathrm{f}^{n-1} 5 \mathrm{~d} \rightarrow 4 \mathrm{f}^{n}$ emission. Such behaviour of excitation spectra is the exception rather than the rule (see Refs. [11,12] for example). In other words, it is atypical peculiarity, which reflects partly the variation of absorption coefficient in the transparency range and the competition in the energy transfer processes to the $4 \mathrm{f}^{n-1} 5 \mathrm{~d}$ and $4 \mathrm{f}^{n}$ emitting levels.

In Refs. [13,14] it was shown that fluorite synthetic crystals demonstrate intensive enough optical absorption in 130-200 nm 


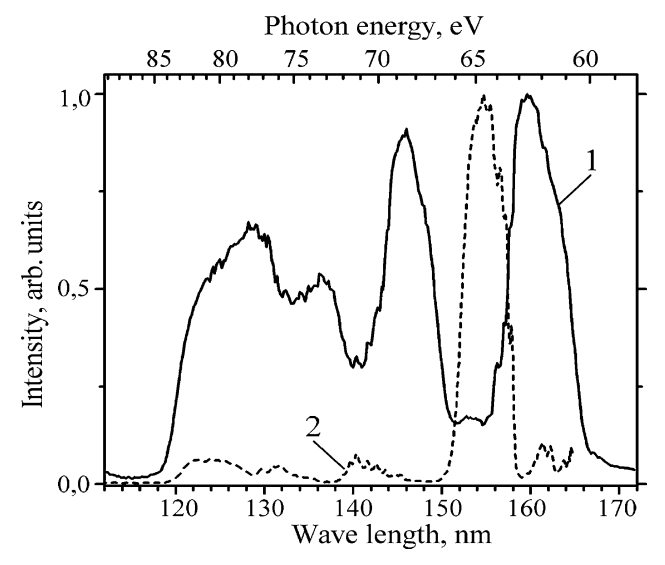

Fig. 4. Excitation spectra for ${ }^{1} \mathrm{G}_{4} \rightarrow{ }^{3} \mathrm{H}_{6}$ emission at $451 \mathrm{~nm}$ (1) and for $4 \mathrm{f}^{11} 5 \mathrm{~d}(\mathrm{HS}) \rightarrow{ }^{3} \mathrm{H}_{6}$ emission at $167 \mathrm{~nm}(2)$ of $\mathrm{Tm}^{3+}$ in $\mathrm{SrF}_{2}: 0.3 \% \mathrm{Tm}^{3+} . T=8 \mathrm{~K}$.

spectral range that is connected with presence of uncontrolled oxygen impurities which are falling into crystals from crucible and residual atmosphere at growing by means of Stokbarger technique. We assume that such oxygen centers (oxygen-vacancy defects and their aggregates) make appreciable contribution to the excitation of $4 \mathrm{f}^{n}$ levels. As a rule, the absorption of oxygen centers is observed as very broad and intensive bands in excitation and absorption spectra. In the case of $\mathrm{RE}^{3+}$ doped crystals these absorption processes compete with intensive absorption bands caused by $4 \mathrm{f}^{n} \rightarrow 4 \mathrm{f}^{n-1} 5 \mathrm{~d}$ transitions. It results in observing atypical peculiarities of excitation spectra for $4 \mathrm{f}^{n} \rightarrow 4 \mathrm{f}^{n}$ emissions. The atypical peculiarities are strongly pronounced for ions having radiative $4 \mathrm{f}^{n-1} 5 \mathrm{~d}$ states (such as $\mathrm{Er}^{3+}$ and $\mathrm{Tm}^{3+}$ ) for which a dominating way for relaxation of excited $4 \mathrm{f}^{n-1} 5 \mathrm{~d}$ states is VUV emission $[4,8]$.

For $\mathrm{RE}^{3+}$ ions having no $4 \mathrm{f}^{n-1} 5 \mathrm{~d} \rightarrow 4 \mathrm{f}^{n}$ emission the energy of excited $4 \mathrm{f}^{n-1} 5 \mathrm{~d}$ states is transferred with high efficiency to the $4 \mathrm{f}^{n}$ levels. In this case, such incidental process, as absorption, connected with oxygen impurity cannot compete with intensity of excitation through direct $4 \mathrm{f}^{n} \rightarrow 4 \mathrm{f}^{n-1} 5 \mathrm{~d}$ transitions. In excitation spectra of such ions the bands of oxygen absorption are either weakly observed (as in the case of $\mathrm{Sm}^{3+}$ ) or completely unobserved (case of $\mathrm{Tb}^{3+}$ ).

Moreover, it is necessary to add that $4 \mathrm{f}^{n} \rightarrow 4 \mathrm{f}^{n}$ emission of $\mathrm{Er}^{3+}$ or $\mathrm{Tm}^{3+}$ has enough high excitation efficiency in the range of long-wavelength fundamental absorption edge of the host. For $4 \mathrm{f}^{n-1} 5 \mathrm{~d} \rightarrow 4 \mathrm{f}^{n}$ emission in contrary such mechanism is suppressed. We assume this phenomenon is connected with autoionization process that is a result of promotion of $4 \mathrm{f}$ electron to high-energy excited 5d-states located in conduction band at absorption. Finally, an exciton-like $\mathrm{Ln}^{4+}+\mathrm{e}^{-}$(bounded) forma- tion is created that relaxes predominantly into the $4 \mathrm{f}$ manifold through dipole-dipole or multipole interactions [1].

\section{Conclusion}

The VUV spectroscopic properties of $\mathrm{Sm}^{3+}, \mathrm{Tb}^{3+}, \mathrm{Er}^{3+}$ and $\mathrm{Tm}^{3+}$ ions doped into $\mathrm{SrF}_{2}$ crystals have been studied under excitation by synchrotron radiation.

It was shown that atypical peculiarities connected with absorption of uncontrolled oxygen centers can be observed in excitation spectra for $4 \mathrm{f}^{n} \rightarrow 4 \mathrm{f}^{n}$ emissions. It reflects an important conclusion about the distinction of the number of mechanisms for excitation of $4 \mathrm{f}^{n}$ or $4 \mathrm{f}^{n-1} 5 \mathrm{~d}$ emitting levels. Whereas $4 \mathrm{f}^{n-1} 5 \mathrm{~d}$ emitting levels can be excited through direct $4 \mathrm{f}^{n} \rightarrow 4 \mathrm{f}^{n-1} 5 \mathrm{~d}$ absorption only the excitation mechanisms for $4 \mathrm{f}^{n} \rightarrow 4 \mathrm{f}^{n}$ emissions are more complicated including also such possibilities as energy transfer via uncontrolled impurities and autoionization processes.

\section{Acknowledgements}

The authors wish to thank G. Stryganyuk (HASYLAB, Germany) and M. Kirm for assistance at SUPERLUMI station and helpful discussions. The work was partly supported by Russian Foundation for Basic Research (grant 05-02-16530).

\section{References}

[1] A.N. Belsky, J.C. Krupa, Displays 19 (1999) 185.

[2] E. Radzhabov, T. Kurobori, J. Phys.: Condens. Matter. 16 (2004) 1871.

[3] L. van Pieterson, M.F. Reid, M.F. Wegh, S. Soverna, A. Meijerink, Phys. Rev. B 65 (2002) 045113

[4] L. van Pieterson, M.F. Reid, G.W. Burdick, A. Meijerink, Phys. Rev. B 65 (2002) 045114

[5] L. van Pieterson, M.F. Reid, A. Meijerink, Phys. Rev. Lett. 88 (2002) 067405.

[6] K.V. Ivanovskikh, V.A. Pustovarov, B.V. Shulgin, M. Kirm, Russ. Phys. J. 48 (2005) 984

[7] K.V. Ivanovskikh, V.A. Pustovarov, B.V. Shulgin, Nucl. Instrum. Meth. A 543 (2005) 229.

[8] K.V. Ivanovskikh, V.A. Pustovarov, M. Kirm, B.V. Shulgin, J. Lumin. 122-123 (2007) 28.

[9] P. Dorenbos, Phys. Rev. B 65 (2000) 15640

[10] A.E. Nikiforov, A.Y. Zakharov, M.Y. Ugryumov, S.A. Kazanskii, A.I. Ryskin, G.S. Shakurov, Phys. Solid State 47 (2005) 1431.

[11] V.N. Makhov, N.M. Khaidukov, N.Y. Kirikova, M. Kirm, J.C. Krupa, T.V. Ouvarova, G. Zimmerer, Nucl. Instrum. Meth. A 470 (2001) 290.

[12] N.M. Khaidukov, N.Y. Kirikova, M. Kirm, J.C. Krupa, V.N. Makhov, E. Negodin, G. Zimmerer, Proc. SPIE 4766 (2002) 154.

[13] V.A. Arkhangelskaya, V.M. Reiterov, L.M. Trofimova, J. Appl. Spectrosc. 32 (1980) 103.

[14] E. Radzhabov, P. Figura, Phys. Stat. Sol (b) 186 (1994) K37. 